Check for updates

Cite this: RSC Adv., 2019, 9, 9093

Received 10th February 2019

Accepted 11th March 2019

DOI: 10.1039/c9ra01071h

rsc.li/rsc-advances

\title{
A mild and efficient method for the synthesis of pyrroles using MIL-53(Al) as a catalyst under solvent-free sonication $\dagger$
}

\author{
Hai Truong Nguyen, (D) a Linh Ho Thuy Nguyen, ${ }^{\text {ab }}$ Tan Le Hoang Doan*ab \\ and Phuong Hoang Tran iD *a
}

\begin{abstract}
A highly efficient method for the synthesis of pyrroles using MIL-53(Al) as a catalyst has been developed under solvent-free sonication. This reaction has a broad substrate scope and high yields were obtained within a short reaction time. Remarkably, no additional additives and volatile organic solvent are required for this method and the MIL-53(Al) could be recovered and reused several times without significant drop-off in catalytic activity.
\end{abstract}

\section{Introduction}

Metal-organic frameworks (MOFs) are a class of crystalline porous materials containing metal clusters (termed secondary building units, SBUs) connected by a variety of organic bridges. $^{1,2}$ These materials have attracted much interest for many potential applications in heterogeneous catalysis due to their exceptional properties including crystallinity, active-site uniformity, and high porosity with permeable channels. ${ }^{3-7}$ Especially, aluminum based-MOFs with highly robust structures have recently emerged as promising catalysts in several organic transformations. ${ }^{\mathbf{8}, 9}$ Among them, the well-known catalyst is MIL-53(Al), whose porous 3D structure with 1D lozengeshaped channels (Fig. 1) is constructed from a connection of infinite trans-chains of corner-sharing (via $\mathrm{OH}$ groups) $\mathrm{AlO}_{4}(\mathrm{OH})_{2}$ octahedra with ditopic organic linker, 1,4-benzenedicarboxylate (BDC). ${ }^{10}$ Because of the exceptional structural properties, the material could play a role as a Brønsted-type $\mathbf{1 1 , 1 2}^{\mathbf{1 1 2}}$ (OH sites) and Lewis-type ${ }^{13}\left(\mathrm{Al}^{3+}\right.$ sites) acid heterogeneous catalyst. Although there have been a wide number of reported researches used MIL-53(Al) for catalysis in alkylation, ${ }^{13}$ cycloaddition, ${ }^{\mathbf{1 4}}$ Mannich reaction, ${ }^{\mathbf{1 2}}$ and cellulose transformation, ${ }^{\mathbf{1 1}}$ the catalytic activity of MIL-53(Al) for organic transformations remains an attractive field.

Pyrroles are important structural motifs present in various biologically active molecules and natural products. ${ }^{15-23}$ There are three commonly used approaches for the synthesis of these essential compounds including Barton-Zard, Paal-Knorr, and

${ }^{a}$ Faculty of Chemistry, University of Science, Vietnam National University - Ho Chi Minh City, 721337, Vietnam.E-mail: thphuong@hcmus.edu.vn

${ }^{b}$ Center for Innovative Materials and Architectures, Vietnam National University - Ho Chi Minh City, 721337, Vietnam.E-mail: dlhtan@inomar.edu.vn

$\dagger$ Electronic supplementary information (ESI) available. See DOI: 10.1039/c9ra01071h
Hantzsch syntheses. Among these approaches, the Paal-Knorr reaction is known as an extremely efficient pathway to produce pyrroles from primary amines and 1,4-dicarbonyl compounds under acidic conditions. Over the past decade, several typical acidic catalysts have been widely employed in the Paal-Knorr reaction including Lewis acids, ${ }^{24-28}$ metal-organic frameworks, ${ }^{29}$ deep eutectic solvents, ${ }^{30}$ Brønsted acids. ${ }^{31,32}$ Despite the potential utility of these catalysts, many of them still suffer from certain drawbacks, including long reaction times, volatile organic solvents, low yields, expensive and unrecyclable catalysts. Due to the advantages of high activity and easy recovery, heterogeneous catalysts have been receiving much attention in the organic synthesis. Herein, we describe the direct synthesis of pyrrole using primary amines and hexa-1,4-dione catalyzed by MIL-53(Al) under solvent-free sonication. The mild reaction conditions, no additional additives, work-up simplicity, catalytic recyclability are the outstanding features of the present work.

\section{Experimental}

\section{General methods}

Powder X-ray diffraction (PXRD) patterns were recorded using a D8 Advance diffractometer equipped with a LYNXEYE detector (Bragg-Brentano geometry, $\mathrm{Cu} \mathrm{K} \alpha$ radiation $\lambda=1.54056 \AA$ ). Thermal gravimetric analysis (TGA) was performed using a TA Instruments Q-500 thermal gravimetric analyzer under airflow with a temperature ramp of $5{ }^{\circ} \mathrm{C} \mathrm{min}^{-1}$. Fourier transform infrared (FT-IR) spectra were measured on a Bruker E400 FT-IR spectrometer using potassium bromide pellets. Low-pressure $\mathrm{N}_{2}$ and $\mathrm{CO}_{2}$ adsorption measurements were carried out on a Quantachrome Autosorb iQ volumetric gas adsorption analyzer. A liquid $\mathrm{N}_{2}$ bath was used for measurements at $77 \mathrm{~K}$. Helium was used as an estimation of dead space. Ultrahighpurity-grade $\mathrm{N}_{2}$, and $\mathrm{He}(99.999 \%$ purity) were used 
throughout adsorption experiments. Solution NMR spectra were recorded on a Bruker Advance-500 MHz NMR spectrometer. Scanning Electron Microscopy (SEM) images were performed on a JEOL JSM-75FCT. Gas chromatography (GC) analyses were performed using Agilent 6890 Series equipped with a flame ionization detector (FID) and a DB-5 column (length $=30 \mathrm{~m}$, inner diameter $=320 \mu \mathrm{m}$, film thickness $=0.25$ $\mu \mathrm{m})$. GC-MS analyses were performed on Agilent GC System 7890 Series, equipped with a mass selective detector Agilent $5973 \mathrm{~N}$ and a capillary DB-5MS column (length $=30 \mathrm{~m}$, inner diameter $=320 \mu \mathrm{m}$, film thickness $=0.25 \mu \mathrm{m}$ ).

\section{Preparation of MIL-53(Al) catalyst}

MIL-53(Al) was hydrothermally synthesized following the reported procedure. ${ }^{33} \mathrm{Al}\left(\mathrm{NO}_{3}\right)_{3} \cdot 9 \mathrm{H}_{2} \mathrm{O}(375 \mathrm{mg}, 0.50 \mathrm{mmol})$ and 1,4-benzenedicarboxylic acid, $\mathrm{H}_{2} \mathrm{BDC},(83.1 \mathrm{mg}, 0.50 \mathrm{mmol}$ ) were dissolved in $1.5 \mathrm{~mL}$ deionized (DI) water in a Teflon-lined steel autoclave. The solution was subsequently heated at $220{ }^{\circ} \mathrm{C}$ for 3 days in an isothermal oven to yield a white precipitate. After cooling the autoclave to room temperature, the white precipitate was obtained by centrifugation and washed five times with DI water. The as-synthesized sample was then evacuated at room temperature for $24 \mathrm{~h}$. The solid was then heated in air at $330{ }^{\circ} \mathrm{C}$ for 3 days for removal of the excessive $\mathrm{H}_{2} \mathrm{BDC}$ adsorbed in the pores.

\section{General procedure for Paal-Knorr reaction}

MIL-53(Al) (10 mg, $5 \mathrm{~mol} \%$ ), aromatic amine (1.0 mmol), actonylacetone $(1.2 \mathrm{mmol})$ was added into a $10 \mathrm{~mL}$ pressurized glass tube. The reaction mixture was sonicated at $80{ }^{\circ} \mathrm{C}$ for an appropriate time. The progress of the reaction was monitored by TLC and GC. After completion of the reaction, the catalyst was filtered from the reaction mixture. The filtrate was diluted with ethyl acetate $(25 \mathrm{~mL})$, washed with $\mathrm{H}_{2} \mathrm{O}(5 \times 15 \mathrm{~mL})$, and dried over $\mathrm{Na}_{2} \mathrm{SO}_{4}$. The solvent was removed under vacuum on a rotary evaporator. The pure product was isolated by flash chromatography ( $n$-hexane, then $10 \%$ ethyl acetate in $n$-hexane). The purity and identity of the pyrrole were confirmed by GC-MS spectrometry, ${ }^{1} \mathrm{H}$ and ${ }^{13} \mathrm{C}$ NMR spectroscopy.

\section{Results and discussion}

The MIL-53(Al) was prepared by a hydrothermal reaction of aluminum chloride and the ditopic linker, 1,4-benzenedicarboxylic acid. After the reaction finished, the suspension was cooled to room temperature, and then the white precipitate was obtained by centrifugation and washed five times with DI water. As-synthesized MIL-53 was heated at $330{ }^{\circ} \mathrm{C}$ for 3 days and activated at $120{ }^{\circ} \mathrm{C}$ for a day to yield the guest-free material. After activation, the purity of MIL-53(Al) framework was determined by powder X-ray diffraction (PXRD) in which the activated PXRD pattern for MIL-53(Al) was in good agreement to that of the simulated MIL-53(Al) (ESI, Fig. S1†). ${ }^{10}$ Thermogravimetric analysis (TGA) was utilized to access the activation procedure. The TGA curve of the activated sample with a single step of the linker decomposition above $500{ }^{\circ} \mathrm{C}$ demonstrated the complete removal of guest molecules in the framework (ESI, Fig. S2 $\dagger$ ). The nitrogen adsorption isotherm of MIL-53(Al) at low pressure and $77 \mathrm{~K}$ exhibited a type-I behavior due to the presence of micropore within the structure and an internal surface area of $1120 \mathrm{~m}^{2} \mathrm{~g}^{-1}$ based on Brunauer-Emmett-Teller (BET) method (ESI, Fig. S3†).

Subsequently, we employed MIL-53(Al) directly to synthesize pyrroles selectively and the desired product was afforded in $96 \%$ yield (Table 1, entry 18). To evaluate the efficiency of catalyst, the model reaction of acetonylacetone with aniline was carried out under solvent-free sonication in the presence of various catalysts.

As can be seen in Table 1, the corresponding product was afforded in a good yield of $67-83 \%$ in the presence of metal halides (Table 1, entries 1-6), while low yields were observed when metal oxides were employed (Table 1, entries 7-12). $\mathrm{HfCl}_{4}$ and $\mathrm{AlCl}_{3}$ provided the corresponding product in high yields, but these metal halides were not recovered after the aqueous work-up. Then, MOFs including MOF-890, MOF-891, MOF-177, ZIF-8, and HKUST-1 were tested in the model reaction and good yields of $80-89 \%$ were observed (Table 1, entries 13-17). MIL53(Al) displayed the best catalytic activity and high stability for the Paal-Knorr synthesis (Table 1, entry 18). However, the reaction could hardly proceed in the absence of a catalyst (Table 1, entry 19). According to these results, we reason that MIL53(Al) acted as an efficient heterogeneous Lewis acid catalyst in this reaction (as shown in Scheme $\mathbf{S 1 \dagger}$ ). Thus, the reaction conditions were optimized in the presence of MIL-53(Al) catalyst under solvent-free sonication (see Table S1-S4 in the ESI $\dagger$ ).

Table 1 The effect of different catalysts in the Paal-Knorr reaction ${ }^{a}$

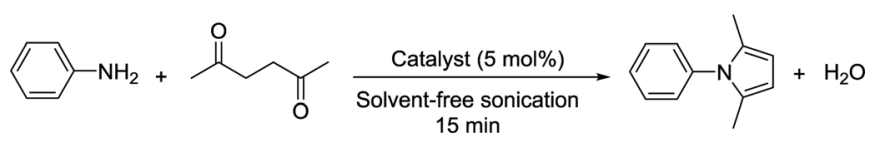

\begin{tabular}{lll}
\hline Entry & Catalyst & Isolated yield (\%) \\
\hline 1 & $\mathrm{CuCl}_{2}$ & 67 \\
2 & $\mathrm{FeCl}_{2}$ & 76 \\
3 & $\mathrm{HfCl}_{4}$ & 83 \\
4 & $\mathrm{FeCl}_{3}$ & 78 \\
5 & $\mathrm{AlCl}_{3}$ & 83 \\
6 & $\mathrm{ZnCl}_{2}$ & 77 \\
7 & $\mathrm{Fe}_{2}$ & 74 \\
8 & $\mathrm{ZnO}_{3}$ & 70 \\
9 & $\mathrm{Al}_{2} \mathrm{O}_{3}$ & 55 \\
10 & $\mathrm{TiO}_{2}$ & 73 \\
11 & $\mathrm{MgO}$ & 14 \\
12 & $\mathrm{CuO}$ & 72 \\
13 & $\mathrm{MOF}-890$ & 80 \\
14 & $\mathrm{MOF}-891$ & 82 \\
15 & MOF-177 & 81 \\
16 & $\mathrm{ZIF-8}$ & 83 \\
17 & $\mathrm{HKUST}-1$ & 89 \\
$\mathbf{1 8}$ & MIL-53(Al) & 96 \\
19 & Non-catalyst & 25
\end{tabular}

${ }^{a}$ Reaction condition: aniline $(1.0 \mathrm{mmol})$, acetonylacetone $(1.2 \mathrm{mmol})$ in the presence of the catalyst ( $5 \mathrm{~mol} \%$ ) under solvent-free sonication. 
Table 2 Synthesis of pyrroles catalyzed by MIL-53(Al) ${ }^{a}$

Entry Amine Time (min) Product<smiles>Nc1ccccc1</smiles><smiles>Cc1ccc(C)n1-c1ccccc1</smiles><smiles>Nc1cc(Cl)cc(Cl)c1</smiles><smiles>Cc1ccc(C)n1-c1cc(Cl)cc(Cl)c1</smiles><smiles>Nc1cc(Cl)ccc1Cl</smiles><smiles>Cc1ccc(C)n1-c1cc(Cl)ccc1Cl</smiles><smiles>Cc1ccc(C)n1-c1ccc(Cl)c(Cl)c1</smiles><smiles>Nc1cc(Br)ccc1Br</smiles><smiles>Cc1ccc(C)n1-c1cc(Br)ccc1Br</smiles><smiles>Nc1ccc(I)cc1</smiles><smiles>Cc1ccc(C)n1-c1ccc(I)cc1</smiles><smiles>Cc1ccccc1N</smiles><smiles>Cc1ccccc1-n1c(C)ccc1C</smiles><smiles>Nc1ccc(O)cc1</smiles><smiles>Cc1ccc(C)n1-c1ccc(O)cc1</smiles><smiles>Nc1cc([N+](=O)[O-])ccc1O</smiles><smiles>Cc1ccc(C)n1-c1cc([N+](=O)[O-])ccc1O</smiles><smiles>Cc1ccc(O)c(N)c1</smiles>

15<smiles>Cc1ccc(O)c(-n2c(C)ccc2C)c1</smiles>

98 
Table 2 (Contd.)

Entry Amine

Time (min)

Product

Isolated yield ${ }^{b}(\%)$

11<smiles>Nc1ccc([N+](=O)[O-])cc1N</smiles><smiles>Nc1ccc([N+](=O)[O-])cc1</smiles><smiles>N#Cc1ccc(N)cc1</smiles><smiles>Nc1ccccc1-c1ccccc1</smiles>

15<smiles>COC(=O)c1ccc(N)cc1</smiles><smiles>NNc1ccccc1</smiles>

16

17<smiles>NNc1ccc([N+](=O)[O-])cc1[N+](=O)[O-]</smiles>

18<smiles>NCCNCCNCCN</smiles><smiles>Cc1ccc(C)n1-c1cc([N+](=O)[O-])ccc1N</smiles>

20<smiles>Cc1ccc(C)n1-c1ccc([N+](=O)[O-])cc1</smiles>

90<smiles>Cc1ccc(C)n1-c1ccc(C#N)cc1</smiles>

98<smiles>Cc1ccc(C)n1-c1ccccc1-c1ccccc1</smiles>

95<smiles>COC(=O)c1ccc(-n2c(C)ccc2C)cc1</smiles>

98<smiles>Cc1ccc(C)n1Nc1ccccc1</smiles>

50<smiles>Cc1ccc(C)n1Nc1ccc([N+](=O)[O-])cc1[N+](=O)[O-]</smiles>

Trace<smiles>Cc1ccc(C)n1CCNCCNCCn1c(C)ccc1C</smiles>

${ }^{a}$ The reaction conditions: amines $(1 \mathrm{mmol})$, acetonylacetone $(1.2 \mathrm{mmol}) .{ }^{b}$ Isolated yield. ${ }^{c}$ Yield of another isomer was obtained in $15 \% .{ }^{d}$ Yield in parenthesis was reported by the reaction with 2.4 equiv. of acetonylacetone.

With the optimized conditions in hand, the scope of was investigated (Table 2). The electronic properties of aromatic amines have little influence on the Paal-Knorr synthesis. Reactions with anilines bearing dihalo groups (Table 2, entries $2-5)$ could provide the desired products in good yields $(>80 \%)$ with prolonged the reaction times (20-30 $\mathrm{min})$. Interestingly, the yield of expected product increased to $96 \%$ when 4 -iodoaniline (Table 2, entry 6) was employed as the substrate. As expected, reactions with anilines bearing electron-donating groups in the aromatic ring (Table 2, entries 7-10) could 
effectively deliver the corresponding products in excellent yields $(>90 \%$ ) with $100 \%$ conversion of substrates. Interestingly, when 4-nitro-o-phenylenediamine was employed as the substrate and the yield of major product was obtained in $75 \%$ (Table 2, entry 11). Remarkably, after the reaction mixtures were exposed to ultrasound for 15-20 min, anilines bearing electronwithdrawing groups can be converted into the corresponding products (Table 2, entry 12-15). The expected products were afforded in moderate yields with phenylhydrazine (Table 2, entry 16). No product was detected with 2,4-dinitrophenylhydrazine (Table 2, entry 17). As expected, the use of 1,2-ethanediamine as the substrate provided the corresponding bispyrrole in $55 \%$ yield; attempts to improve the reaction yield by using the molar of acetonylacetone to greater than two equiv. were successful (Table 2, entry 18). Furthermore, the current protocol was also investigated on a $10 \mathrm{mmol}$ scale reaction between aniline and acetonylacetone, which provided the corresponding product in $95 \%$ yield. Consequently, the present method can be potentially applied to the industrial processes.

The recovery and reuse of the developed MIL-53(Al) catalyst in the Paal-Knorr synthesis can be achieved by a simple filtration. A little decrease of the catalytic activity was observed after the fourth cycle (Fig. 2). These results demonstrated that the MIL-53(Al) could be reused at least four times without significant decline of catalytic activity. PXRD analysis of MIL-53(Al)

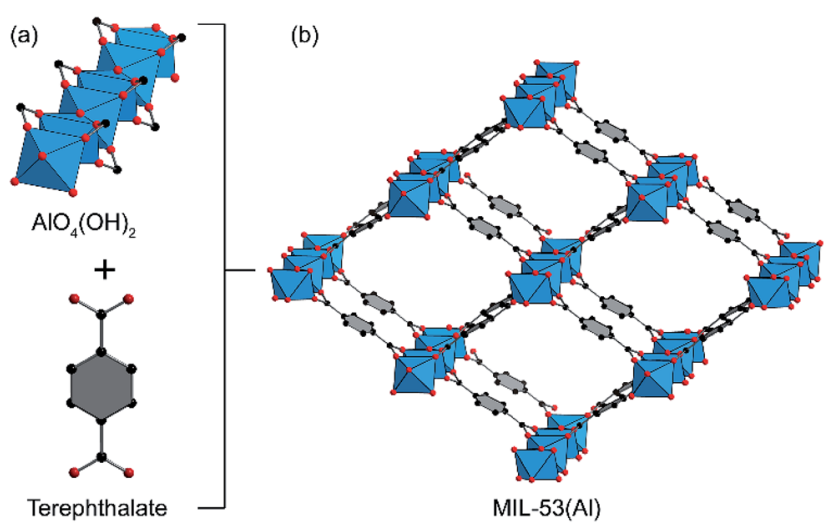

Fig. 1 The combination of an infinite octahedral trans-chain metal building unit and ditopic linker (a) to form the porous 3D structure with 1D rhombic channels (b). Atom colors: C, black; O, red; Al, blue; $\mathrm{H}$ atoms are omitted for clarity.

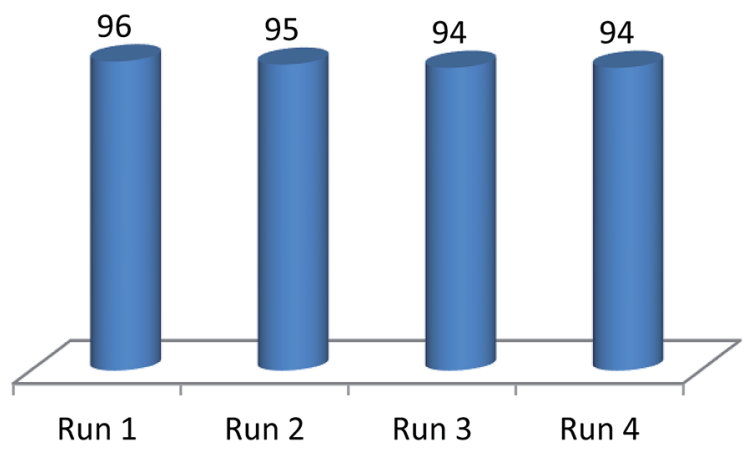

Fig. 2 Recycling of MIL-53(Al). revealed that the crystallinity and integrity of this catalyst was maintained after the fourth cycle (please see Fig. S6 in ESI $\dagger$ ).

\section{Conclusion}

In conclusion, we have developed a highly efficient protocol for cyclocondensation between primary amines and acetonylacetone using cheap and easily-prepared MIL-53(Al) under solventfree sonication. To the best of our knowledge, this is the first example of Paal-Knorr synthesis catalyzed by a heterogeneous MIL-53(Al) under sonication. It is noteworthy that the additional additives and volatile organic solvents are not required for this method. Moreover, MIL-53(Al) employed in catalytic amount and can be recycled at least four times without significant decrease in its catalytic activity. The detailed mechanistic study is in progress within our laboratory.

\section{Conflicts of interest}

There are no conflicts to declare.

\section{Notes and references}

1 A. Schoedel, M. Li, D. Li, M. O'Keeffe and O. M. Yaghi, Chem. Rev., 2016, 116, 12466-12535.

2 C. Wang, X. Liu, N. Keser Demir, J. P. Chen and K. Li, Chem. Soc. Rev., 2016, 45, 5107-5134.

3 J. Liu, L. Chen, H. Cui, J. Zhang, L. Zhang and C.-Y. Su, Chem. Soc. Rev., 2014, 43, 6011-6061.

4 Z. Hu and D. Zhao, CrystEngComm, 2017, 19, 4066-4081.

5 L. H. T. Nguyen, T. T. Nguyen, H. L. Nguyen, T. L. H. Doan and P. H. Tran, Catal. Sci. Technol., 2017, 7, 4346-4350.

6 H. L. Nguyen, T. T. Vu, D.-K. Nguyen, C. A. Trickett, T. L. H. Doan, C. S. Diercks, V. Q. Nguyen and K. E. Cordova, Communications Chemistry, 2018, 1, 70.

7 T. A. To, Y. H. Vo, H. T. T. Nguyen, P. T. M. Ha, S. H. Doan, T. L. H. Doan, S. Li, H. V. Le, T. N. Tu and N. T. S. Phan, J. Catal., 2019, 370, 11-20.

8 L. M. Aguirre-Díaz, D. Reinares-Fisac, M. Iglesias, E. Gutiérrez-Puebla, F. Gándara, N. Snejko and M. Á. Monge, Coord. Chem. Rev., 2017, 335, 1-27.

9 A. U. Czaja, N. Trukhan and U. Muller, Chem. Soc. Rev., 2009, 38, 1284-1293.

10 T. Loiseau, C. Serre, C. Huguenard, G. Fink, F. Taulelle, M. Henry, T. Bataille and G. Férey, Chem.-Eur. J., 2004, 10, 1373-1382.

11 G. Zi, Z. Yan, Y. Wang, Y. Chen, Y. Guo, F. Yuan, W. Gao, Y. Wang and J. Wang, Carbohydr. Polym., 2015, 115, 146-151.

12 M. Zongcheng, Q. Chao, W. Liangshi, A. M. Wensley and L. Yi, Appl. Organomet. Chem., 2017, 31, e3569.

13 E. Rahmani and M. Rahmani, Ind. Eng. Chem. Res., 2018, 57, 169-178.

14 R. Li, Y. Jiang, J. Zhao, D. Ramella, Y. Peng and Y. Luan, RSC Adv., 2017, 7, 34591-34597.

15 S. Michlik and R. Kempe, Nat. Chem., 2013, 5, 140-144.

16 B. T. Parr, C. Economou and S. B. Herzon, Nature, 2015, 525, 507-510. 
17 X. B. Ding, M. A. Brimble and D. P. Furkert, Org. Biomol. Chem., 2016, 14, 5390-5401.

18 L. Tao, Z.-J. Wang, T.-H. Yan, Y.-M. Liu, H.-Y. He and Y. Cao, ACS Catal., 2016, 959-964, DOI: 10.1021/acscatal.6b02953.

19 B. Xu, G. Li, J. Li and Y. Shi, Org. Lett., 2016, 18, 2028-2031.

20 M. Fleige and F. Glorius, Chem.-Eur. J., 2017, 23, 1077310776.

21 Z. Gong, Y. Lei, P. Zhou and Z. Zhang, New J. Chem., 2017, 41, 10613-10618.

22 A. Kornienko and J. J. La Clair, Nat. Prod. Rep., 2017, 34, 1051-1060.

23 L. Zhang, J. Zhang, J. Ma, D.-J. Cheng and B. Tan, J. Am. Chem. Soc., 2017, 139, 1714-1717.

24 A. Rahmatpour, Appl. Organomet. Chem., 2011, 25, 585-590.

25 K. Aghapoor, L. Ebadi-Nia, F. Mohsenzadeh, M. Mohebi Morad, Y. Balavar and H. R. Darabi, J. Organomet. Chem., 2012, 708-709, 25-30.
26 A. A. Jafari and H. Mahmoudi, Environ. Chem. Lett., 2012, 11, 157-162.

27 A. Rahmatpour, J. Organomet. Chem., 2012, 712, 15-19.

28 A. Kamal, S. Faazil, M. Shaheer Malik, M. Balakrishna, S. Bajee, M. R. H. Siddiqui and A. Alarifi, Arabian J. Chem., 2016, 9, 542-549.

29 N. T. S. Phan, T. T. Nguyen, Q. H. Luu and L. T. L. Nguyen, J. Mol. Catal. A: Chem., 2012, 363-364, 178-185.

30 S. Handy and K. Lavender, Tetrahedron Lett., 2013, 54, 43774379.

31 L. Akelis, J. Rousseau, R. Juskenas, J. Dodonova, C. Rousseau, S. Menuel, D. Prevost, S. Tumkevičius, E. Monflier and F. Hapiot, Eur. J. Org. Chem., 2016, 2016, 31-35.

32 F. Bonyasi, M. Hekmati and H. Veisi, J. Colloid Interface Sci., 2017, 496, 177-187.

33 X. Qian, B. Yadian, R. Wu, Y. Long, K. Zhou, B. Zhu and Y. Huang, Int. J. Hydrogen Energy, 2013, 38, 16710-16715. 